\title{
PHYSICAL EXERCISE IS MORE EFFECTIVE THAN HRT IN IMPROVING LIPID PROFILE STATUS IN POSTMENOPAUSAL WOMEN
}

\author{
TABASSUM FERDOUS ${ }^{1}$, NASIM JAHAN ${ }^{2}$, NAYMA SULTANA ${ }^{3}$, HAFIZA AKHTER ${ }^{4}$, MOHAMMED MONTASIR ISLAM ${ }^{5}$, \\ MOHAMMED RAJEEB ALAM ${ }^{6}$ \\ ${ }^{1}$ Assistant Professor, Department of Physiology, Nightingale Medical College, Ashulia, Dhaka. \\ ${ }^{2}$ Professor and Head, Department of Physiology, Sir Salimullah Medical College SSMC, Mitford, Dhaka. \\ ${ }^{3}$ Associate Professor, Department of Physiology, Sir Salimullah Medical College SSMC, Mitford, Dhaka. \\ ${ }^{4}$ Assistant Professor, Department of Physiology, Dr Sirajul Islam Medical College, Dhaka. \\ ${ }^{5}$ Associate Professor, Department of Physiology, Central Medical College, Comilla. \\ ${ }^{6}$ Consultant, Lions Eye Hospital, Agargaon, Dhaka.
}

\begin{abstract}
Disturbances of lipid profile in postmenopausal women may occur due to hormonal changes and physical inactivity which ultimately increases the risk of atherosclerosis, CHD and MI. Physical exercise may play a significant role in the management of dyslipidemia among postmenopausal women than HRT The study was carried out to compare and contrast between the effects of physical exercise and HRT in improving lipid profile status among postmenopausal women. This study was carried out in the Department of Physiology, Sir Salimullah Medical College, Dhaka, from $1^{\text {st }}$ January, 2009 to $31^{\text {st }}$ December, 2009. A total number of 90 postmenopausal women having age ranged from 50-60 years were included in the study. Among 90 postmenopausal women, 30 were performing regular physical exercise, 30 were receiving HRT and 30 were sedentary postmenopausal women without receiving HRT. Lipid profile such as TC, HDL-C, LDL-C, TG and fasting blood sugar of all the participants were estimated in Physiology laboratory, SSMC Mitford, Dhaka. The statistical analysis was done by using appropriate test as applicable. Mean serum TC, $L D L-C$ and TG were significantly $(p<0.001)$ higher and mean $H D L-C$ was significantly $(p<0.001)$ lower in sedentary postmenopausal women than those of postmenopausal women with regular physical exercise and postmenopausal women receiving HRT. Again, TC, LDL-C and TG were comparative higher in postmenopausal women receiving HRT than those of postmenopausal women with regular physical exercise and HDL-C were almost similar among these two groups of women. Conclusion: Physical exercise could be more effective than HRT in improving lipid profile status in postmenopausal women.
\end{abstract}

Key words: Lipid profile, Postmenopausal women, Physical exercise.

(Bangladesh J Physiol Pharmacol 2011;27(1\&2):9-12.)

\section{INTRODUCTION}

Lipid profile abnormalities in postmenopausal women is a common health hazard all over the world. ${ }^{1}$ Due to estrogen deficiency and lack of physical exercise alteration in lipid metabolism occurs among these group of women which ultimately leads to all causes of morbidity \& mortality. ${ }^{2}$

Alteration of lipid metabolism with increase serum levels of total cholesterol (TC), lipoprotein and triglyceride may occur in postmenopausal women which are highly favorable factors for atherogenesis ${ }^{3}$. Again increase level of VLDL-C and LDL-C are found among postmenopausal women. ${ }^{3,4}$

Address for correspondence: Dr. Tabassum Ferdous, Assistant Professor, Department of Physiology, Nightingale Medical College, Ashulia, Dhaka. E-mail: tabassumferdous21@gmail.com
Physical exercise or HRT may play a significant role in the management of adverse changes in lipid profile among post menopausal women. ${ }^{2}$ Physical exercise improves lipid profile by increasing $\mathrm{HDL}-\mathrm{C}$ and by it decreasing, TC, LDL-C, VLDL-C and TG among postmenopausal women. ${ }^{2,5}$ Again, HRT have a favorable effect on lipid profile status among postmenopausal women. Moreover, HRT in postmenopausal women can improve serum cholesterol levels by decreasing LDL-C and increasing HDL-C levels thereby reducing CHD risk by $50 \%{ }^{6}$

But the hazards of prolonged use of HRT may results carcinoma in breast and endometriun, genital bleeding, endometrial hyperplasia, thromboembolism, hypertension, gallbladder disease, stroke etc., Moreover, HRT is not suited for all women and it is contraindicated in several conditions. Again, it is also 
difficult to maintain the dose and timing of taking the drug regularly.

It has been observed that, physical exercise may be safe and effective alternative to HRT in improving lipid profile among postmenopausal women, thereby reducing CVD mortality among these group of women. ${ }^{2}$ Again, performing physical exercise is safest, easiest, less expensive and has no such side effect like HRT supplementation. ${ }^{9}$

Postmenopausal syndrome and complications are increasing day by day throughout the world, especially in Bangladeshi women. Most of this complications arising may be due to abnormal lipid profile status. Although Some study has been done on this regard in abroad, 2,4,9 but no such published data has yet been available on this aspect in our country. Again, the finding of this study may give information to the physicians for proper management of the women with postmenopausal syndrome. Moreover, it is intended to create awareness among healthy adult women to prevent and also to minimize the risk of postmenopausal syndrome. So this study was undertaken.

\section{METHODOLOGY}

This cross sectional study was carried out in the department of physiology, Sir Salimullah Medical College, Dhaka between $1^{\text {st }}$ January 2009 to $31^{\text {st }}$ December 2009. A total number of 90 subjects were taken in this study, and all of them belonged to middle socioeconomic status. Among the 90 postmenopausal women, age ranged from 50-60 yrs were included in this study which was further divided into group $A$ consisting of 30 sedentary postmenopausal women without HRT (Control), group B consisting of 30 postmenopausal women with regular physical exercise (Study) and group C consisting 30 postmenopausal women receiving HRT (Study). Protocol of this study was approved by the Institutional Ethics Committee (IEC) of Sir Salimullah Medical College, Dhaka. All the postmenopausal women were selected from known relatives and associates and the postmenopausal women receiving HRT were collected from Central Hospital, Dhanmondi, Dhaka. Subjects having history of Hypertension, Diabetes Mellitus, Tuberculosis, Heart disease, Renal disease, other acute and chronic diseases, alcohol users, using prescribed medicine were excluded from this study. After selection of the subjects, the objectives and benefits of the study were explained to each subject and written informed consents were taken from the subjects. Detail personal, dietary, medical, family, socioeconomic, occupational and drug history of each subject were recorded in a prefixed questionnaire and thorough physical examinations were also done and documented. Height and weight of the subjects were measured for the calculation of BMI. With all aseptic precautions, $4 \mathrm{ml}$ of venous blood was drawn from medical cubical vein by disposable syringe. It was kept in a clean dry glass test tube and 30 minutes were allowed for clot formation. Then blood was centrifuged at $3000 \mathrm{rpm}$ for 30 minutes. After that supernatant serum was collected in labeled eppendrof tube and preserved in the refrigerator at $-20^{\circ} \mathrm{C}$. Then estimation of fasting blood sugar and lipid profile were done by auto analyzer in the laboratory of Department of physiology, SSMC. The statistical analysis was done by one way ANOVA (Post Hoc) test, Boneferroni test, Chisquare $\left(X^{2}\right)$ test, Fisher's exact test by using SPSS Programme, Version-15.

\section{RESULTS}

All the groups were matched for age. Again, no significant difference of BMI was observed among all the 3 groups of postmenopausal women. (Table I).

The mean TC, LDL-C, VLDL-C and TG was significantly $(p<0.001)$ higher in group $A$ in comparison to those of group $B$ and $C$. Whereas, all of these value were higher in group $C$ in comparison to group $B$, but was not statistically significant (Table-II).

The mean serum HDL-C level was significantly (0.001) lower in group $A$ in comparison to those of group B and C. Again, HDL-C levels were almost similar and showed no significant difference between group $B$ and $\mathrm{C}$.

Table I

Mean $\pm S D$ of Age and BMI in different groups $(n=90)$

\begin{tabular}{lccc}
\hline Group & $\mathbf{n}$ & $\begin{array}{c}\text { Age } \\
\text { (years) }\end{array}$ & $\begin{array}{c}\text { BMI } \\
\left(\mathbf{k g} / \mathbf{m}^{\mathbf{2}}\right)\end{array}$ \\
\hline Group A & 30 & $54.50 \pm 2.22$ & $22.12 \pm 0.60$ \\
& & $(51-59)$ & $(20.55-22.89)$ \\
\hline Group B & 30 & $54.53 \pm 2.08$ & $22.13 \pm 0.75$ \\
& & $(51-59)$ & $(19.92-22.89)$ \\
\hline Group C & 30 & $55.60 \pm 2.14$ & $21.86 \pm 1.30$ \\
& & $(52-60)$ & $(17.58-22.89)$ \\
\hline
\end{tabular}


Statistical analysis

\begin{tabular}{lccc}
\hline Group & $\mathbf{n}$ & $\begin{array}{c}\text { Age } \\
(\mathbf{p} \text { value })\end{array}$ & $\begin{array}{c}\text { BMI } \\
(\mathbf{p} \text { value })\end{array}$ \\
\hline Group A vs Group B & $0.999^{\mathrm{ns}}$ & $0.999^{\text {ns }}$ \\
Group A vs Group C & $0.999^{\text {ns }}$ & $0.999^{\text {ns }}$ \\
Group B vs Group C & $0.333^{\text {ns }}$ & $0.999^{\text {ns }}$ \\
\cline { 2 - 3 }
\end{tabular}

Group A = Sedentary postmenopausal women without HRT (control)

Group $\mathrm{B}=$ Postmenopausal women with regular physical exercise (study)

Group C = Postmenopausal women receiving HRT (study)

$* * *=$ Significant at $\mathrm{p}<0.001 ; \quad \mathrm{ns}=$ Not significant; $\quad \mathrm{n}=$ total number of the subject

Table II

Mean $\pm S D$ of Serum lipid levels in different groups $(n=90)$

\begin{tabular}{l|ccccc}
\hline Group & $\boldsymbol{n}$ & $\boldsymbol{T C}(\boldsymbol{m g} / \boldsymbol{d l}$ & $\boldsymbol{H D L}(\boldsymbol{m g} / \boldsymbol{d l}$ & $\mathbf{L D L}(\boldsymbol{m g} / \boldsymbol{d l}$ & $\mathbf{T G}(\mathbf{m g} / \mathbf{d l})$ \\
\hline Group A & 30 & $218.33 \pm 57.79$ & $34.33 \pm 3.97$ & $149.81 \pm 63.94$ & $170.93 \pm 49.40$ \\
& & $(129-375)$ & $(28-48)$ & $(51.4-309.0)$ & $(100-283)$ \\
Group B & 30 & $147.97 \pm 25.02$ & $40.60 \pm 5.61$ & $87.96 \pm 22.23$ & $97.05 \pm 28.48$ \\
& & $(100-197)$ & $(31-50)$ & $(50-134)$ & $(60-170)$ \\
Group C & \multirow{3}{*}{30} & $152.93 \pm 32.01$ & $40.87 \pm 6.08$ & $88.25 \pm 30.86$ & $119.77 \pm 25.57$ \\
& & $(109-265)$ & $(30-50)$ & $(50.4-201.6)$ & $(75-155)$ \\
\hline
\end{tabular}

Statistical analysis

\begin{tabular}{|c|c|c|c|c|}
\hline Groups & $\begin{array}{c}T C(\mathrm{mg} / \mathrm{dl}) \\
\text { (p value) }\end{array}$ & $\begin{array}{l}H D L(m g / d l) \\
\text { (p value) }\end{array}$ & $\begin{array}{l}L D L(m g / d l) \\
\text { (p value) }\end{array}$ & $\begin{array}{l}\mathrm{TG}(\mathrm{mg} / \mathrm{dl}) \\
\text { ( } \mathrm{p} \text { value) }\end{array}$ \\
\hline Group A vs Group B & $0.001 * * *$ & $0.001 * * *$ & $0.001 * * *$ & $0.001^{* * *}$ \\
\hline Group A vs Group C & $0.001 * * *$ & $0.001 * * *$ & $0.001 * * *$ & $0.001^{* * *}$ \\
\hline Group B vs Group C & $0.999^{\text {ns }}$ & $0.999^{\text {ns }}$ & $0.999^{\text {ns }}$ & $0.079^{\text {ns }}$ \\
\hline
\end{tabular}

Group A = Sedentary postmenopausal women without HRT (control)

Group B = Postmenopausal women with regular physical exercise (Study)

Group $\mathrm{C}=$ Postmenopausal women receiving HRT (Study)

$* * *=$ Significant at $\mathrm{p}<0.001 ; \quad$ ns=Not significant;

$\mathrm{n}=$ total number of the subject

\section{DISCUSSION}

In this study, serum TC, LDL-C, and TG were significantly higher and HDL-C was significantly lower among sedentary postmenopausal women in comparison to postmenopausal women with regular physical exercise and postmenopausal women with HRT. But all these parameters were comparatively improved among postmenopausal women with regular physical exercise in comparison to postmenopausal women with HRT, but was not statistically significant. This finding is in consistent with that of some other researchers. ${ }^{3,10}$ On the contrary, some other groups of investigators observed no significant difference of HDL-
C level among postmenopausal women and premenopausal women. ${ }^{11}$ This discrepancy might be due to the postmenopausal study population was of higher age group (65 26 years), but in the present study, the age of the postmenopausal study population was from 50-60 years.

Some researchers suggested, physical activity is a lipid lowering factor. ${ }^{12}$ It has been reported that, regular physical exercise increases serum HDL-C and decreases serum TC, LDL-C and TG level among postmenopausal women. ${ }^{13,14}$ Again, HDL-C transport excess cholesterol from peripheral tissues to the liver for excretion, a process known as reverse cholesterol transport ${ }^{1}$. 
Moreover, exercise increases fat utilization for energy, thereby create a physiologic state that is beneficial to lipid metabolism.5,15 Furthermore, regular physical exercise may improve insulin sensitivity independent of total weight loss. ${ }^{16}$ In the light of present accepted views, insulin sensitive tissues also contain GLUT-4 vesicles that move into cell membrane in response to exercise and are independent of the action of insulin. This is why exercise lowers blood glucose level. ${ }^{15,16}$

Again, different researchers considered HRT as a cardio protective for postmenopausal women. ${ }^{17}$ Moreover, it has been observed that HRT in postmenopausal women can improve cholesterol by increasing HDL-C and by decreasing LDL-C levels. They also suggested that, this increase in HDL-C levels might be due to estrogen induced inhibition of hepatic lipase, the enzyme which destroy HDL-C. ${ }^{18}$ Furthermore, HRT decreases cholesterol levels by increasing the number of LDL-C receptors in the liver resulting in increased hepatic removal of cholesterol from blood. ${ }^{19}$

However, many hazards and complications may arise from prolong use of HRT such as endometrial carcinoma, breast carcinoma, genital bleeding, endometrial hyperplasia, hypertension, thromboembolism, gall bladder disease, stroke etc. ${ }^{18,19}$ Moreover, HRT is not suited for all women and it is contraindicated several conditions such as undiagnosed abnormal vaginal bleeding, breast lump, myocardial infarction (MI), Thrombo embolism etc. ${ }^{20}$ Again, it is also difficult to maintain the dose and timing of taking the drug regularly.

In the present study, improvement of dyslipidemia were more pronounced in postmenopausal women with Regular Physical exercise group in comparison to those of postmenopausal women with HRT group. Furthermore, it was observed that Physical exercise was more effective than that of HRT in improving lipid profile status as supported by comparing these parameters between postmenopausal women performing physical exercise \& postmenopausal women receiving HRT.

\section{CONCLUSION}

From this study, it can be concluded that, physical exercise was more effective than that of HRT in lowering lipid levels among postmenopausal women. Again, physical exercise is the safest, easiest, less expensive and without having any complication for lipid lowering factor in postmenopausal women. So, regular optimal physical exercise can be used as effective alternative to HRT and thereby reduces CVD risk and improve daily life style.

\section{REFERENCES}

1. Ashen MD, Blumenthal RS. Low HDL cholesterol levels. N Eng J Med 2005; 353:1252-60

2. Barclay L. Physical activity improves lipid profile in postmenopausal women. Menopause 2007; 14: 115-122

3. Barrett-Connor E. Bush TL. Estrogen and coronary heart disease in women. JAMA 1991;265(4): 1861-1867.

4. Carr MC. The emergence of the metabolic syndrome with menopause. The Journal of clinical Endocrinology and Metabolism. 2003;88(6):2404-2411.

5. Creatsas G, Christodoulkos G, Lambrinoudaki I. Cardiovascular disease: screening and management of the a-symptomatic high-risk postmenopausal women. Maturitas 2005;15:52.

6. Feng $Y$, Hong X, Wilker E, Li Z, Zhang W, Jin D, Liu X, Zang T, $\mathrm{Xu} \mathrm{X}, \mathrm{Xu} \mathrm{X}$. Effects of age at menarche, reproductive years and menopause on metabolic risk factor for cardiovascular disease. Atherosclerosis 2008; 196(2):590-7.

7. Folsom AR. Mink PJ, Sellers TA, Ping H, Zheng W, Polter JD. Hormone replacement therapy and morbidity and mortality in a prospective study in postmenopausal women. American Journal of Public Health 1995;85:1128-1138.

8. Ganong WF. Review of Medical Physiology. $22^{\text {nd }}$ eds. USA McGraw-Hill, 2005

9. Grodstein F, Stampfer MJ; Manson JE, Colditz GA, Willett WC, Rosner B, Speizer FE, Hennekens CH. Postmenopausal estrogen and progestin use and the risk of cardiovascular disease. N Eng J Med 1996;335:453-61.

10. Haddock BL, Marshak HP, Mason J], Blix G. The effect of hormone replacement therapy and exercise on cardiovascular, disease risk factors in postmenopausal women. Sports Med 2000;29(I):39-49.

11. Horton ES. Exercise and physical training: effects on insulin sensitivity and glucose metabolism. Diabetes Metab Rev 1986;2:1-17.

12. Jones NL, Judd HL. Menopause and postmenopause. In: Decherney $\mathrm{AH}$ and Nathan L Current obstetric and gynecologic diagnosis and treatment. $9^{\text {th }}$ eds. New York: McGraw-Hill companies, 2003.

13. Kumar $P$, Malhotra. N. Jeffcoats Principles of Gynecology. $7^{\text {th }}$ eds. New Delhi: .Jaypee brothers medical publishers Ltd. 2008.

14. Lazovic M, Devecerski G, Jovic S, Cutovic M, Svirtlih L, Lazovic $M$. Effects of physical training on the lipid profile of patients after myocardial infarction. Med Pregl 2006;59(1):19-22.

15. Matthan NR. Jalbert SM, Lamon-Fava S, Dolnikowski GG, Welty FK, Barrett HR, Schaefer EJ, Lichtenstein AH. TRL, IDL, and LDL apolipoprotein B-100 and HDL apolipoprotein A-1 kinetics as a function of age and menopausal status. Atherosclerosis, Thrombosis and Vascular Biology 2005;25:1691-1696.

16. Olivera A, Filho JM. Nutritional status and lipid profile of postmenopausal women with coronary heart disease. Arq Bras Cadiol 2005;84(4):4.

17. Shah PK, Kaul S, Nilsson J, Creek B. Exploiting the vascular protective effects of high-density lipoprotein and its apolipoproteins: an idea whose time for testing is coming. Circulation 2001; 104:2376-83.

18. Stefanick ML, Mackey S, Sheehan M, Ellsworth N, Haskell WL, Wood PD. Effects of diet and exercise in men and postmenopausal women with low levels of HDL-cholesterol and high levels of LDL cholesterol. New Eng J Med 1998;339:12-20.

19. Tikkanen M, Nikkala EA, Kausi T, Sipinen S. High density lipoprotein-2 and hepatic lipase: reciprocal changes produced by estrogen and norgestrel. J Clin Eduocrinol Metabol 1982;54:1113-37.

20. Usoro CA, Adikwura CC, Usoro IN, Nsonwu AC. Lipid profile of postmenopausal women in Calabar, Nigeria. Pakistan Journal of Nutrition 2006;5(1):79-82. 